\title{
Pemikiran Ibnu Miskawaih Tentang Konsep Pendidikan Karakter Akhlak
}

\author{
Ujud Supriaji \\ Universitas Ma'arif Nahdlatul Ulama Kebumen \\ ujud027@gmail.com
}

\begin{abstract}
Abstrak
Penelitian ini termasuk penelitian kualitatif, yang jenisnya termasuk kajian pustaka atau library research yakni mengkaji dan meneliti literatur-literatur yang relevan sesuai dengan kajian, seperti buku atau e-book, majalah atau koran, artikel, dan lainnya yang memuat tentang biografi Ibnu Miskawaih. Ibnu Miskawaih adalah salah seorang cendekiawan Muslim yang berkonsentrasi pada bidang filsafat akhlak. Dia lahir di Iran pada tahun 330 H/932 M dan meninggal tahun 421 H/1030 M. Penjelasan biografi, karya, dan konsep pemikiran mengenai Ibnu Miskawaih masuk dalam pembahasan artikel ini. Sedangkan Penelitian ini bertujuan untuk mendeskripsikan biografi Ibnu Miskawaih, Untuk Mendeskripsikan apa saja karya ibnu miskawaih, dan Bagaimana Pemikiran Ibnu Miskawaih tentang Konsep Pendidikan Kharakter-Akhlak.Dari hasil penelitian dapat disimpulkan bahwa Ibnu Miskawaih adalah salah seorang cendekiawan Muslim yang berkonsentrasi pada bidang filsafat akhlak. Dia lahir di Iran pada tahun 330 H/932 M dan meninggal tahun $421 \mathrm{H} / 1030 \mathrm{M}$, Menurut Ibnu Miskawaih, akhlak adalah keadaan jiwa seseorang yang mendorongnya untuk melakukan perbuatan-perbuatan tanpa melalui pertimbangan pikiran terlebih dahulu. Karakteristik pemikiran Ibnu Miskawaih dalam pendidikan akhlak secara umum dimulai dengan pembahasan tentang akhlak (karakter/watak). Menurutnya watak itu ada yang bersifat alami dan ada watak yang diperoleh melalui kebiasaan atau latihan. Dia berpikir bahwa kedua watak tersebut hakekatnya tidak alami meskipun kita lahir dengan membawa watak masing-masing, tetapi sebenarnya watak dapat diusahakan melalui pendidikan dan pengajaran.
\end{abstract}

Kata kunci: Ibnu Miskawaih, Biografi, Pemikiran

\begin{abstract}
This research includes qualitative research, the type of which includes literature review or library research, namely examining and researching relevant literature in accordance with the study, such as books or e-books, magazines or newspapers, articles, and others that contain the biography of Ibn Miskawaih. Ibn Miskawaih is a Muslim scholar who concentrates on the field of moral philosophy. He was born in Iran in $330 \mathrm{H} / 932 \mathrm{AD}$ and died in $421 \mathrm{H} / 1030 \mathrm{AD}$. A biography explanation, works, and concepts of thought about Ibn Miskawaih are included in the discussion of this article. Meanwhile, this study aims to describe the biography of Ibn Miskawaih, to describe what Ibn Miskawaih's works are, and how Ibn Miskawaih thinks about the concept of character education. He was born in Iran in the year 330 H/932 AD and died in 421 H/1030 AD. According to Ibn Miskawaih, morality
\end{abstract}


is the state of a person's soul that encourages him to perform actions without prior thought. The characteristics of Ibn Miskawaih's thought in moral education in general begin with a discussion of morals (character/character). According to him, there is a character that is natural and there is a character that is acquired through habit or practice. He thinks that these two characters are not naturally natural even though we are born with our own character, but actually character can be cultivated through education and teaching.

Keywords: Ibn Miskawaih, Biography, Thought

\section{Pendahuluan}

Etika dan jiwa merupakan salah satu pokok bahasan dalam filsafat. Etika merefleksikan bagaimana manusia harus hidup agar ia berhasil sebagai manusia. Karena itu tidak mengherankan bahwa hampir semua filsuf besar juga menulis dalam bidang etika. Mengapa etika dan jiwa dibahas dalam filsafat dan disepakati merupakan cabang filsafat, etika dalam cabang filsafat tidak mempersoalkan keadaan manusia, melainkan mempersoalkan bagaimana manusia harus bertindak, tetapi tindakan manusia itu, keadaan manusia itu sendiri dimaknai dengan jiwa, berarti etika dan jiwa merupakan dua hal yang saling berkaitan. Bahkan dipahami bahwasanya etika lahir dari jiwa, karena tujuan etika tidak sekadar hanya mengetahui pandangan atau teori, ilmu, tetapi juga memengaruhi dan mendorong manusia supaya membentuk hidup suci dan menghasilkan kebaikan dan kesempurnaan serta memberi mamfaat kepada sesama manusia. Dengan kata lain etika mendorong kehendak agar berbuat baik (Amin: 1993).

Tidak lama menjelang Islam lahir, agama Masehi telah memiliki kekuatan politik yang begitu besar di bawah kaisar Yustinius di Konstantinopel. Dengan kekuasaannya agama ini kemudian melarang kepada publik agar tidak mempelajari filsafat, karena ajarannya dianggap bertentangan dengan ajaran agama. Sebagai akibat dari kebijakan inilah maka beberapa ahli pikir yang merasa terbelenggu kebebasannya dalam mengekspresikan pemikiran-pemikirannya melakukan eksodus ke Persia. Sebaliknya, Maha raja Persia dengan sukarela menerimanya untuk tinggal di dalam daerah kekuasaannya, sehingga wajar apabila tidak lama berselang kemudian berdirilahpusat-pusat studi filsafat di daerah yang baru tersebut. Salah satu diantaranya di kota Jundishapur yang letaknya tidak jauh dari Baghdad yang didirikan pada tahun 762 M. (Harun Nasution, 1973)

Setelah Islam lahir langsung bisa menguasai daerah tersebut, kemudian pada masa keksuasaan islam di bawah Bani Abbas (al-Ma'mun dan seterausnya) munculah pemikiranpemikiran baru sebagai akibat dari adanya pergumulan dan interaksi antara kedua budaya tersebut. (Ibrahim Madkur , 1991) Maka munculah sejarah beberapa ilmuwan dan filosof Islam yang cukup fenomenal dan populer. Ia dikenal bukan hanya di dunia Muslim, tetapi juga di dunia Barat dan salah satunya adalah Ibnu Miskawaih.

Ibnu Miskawaih dikenal tidak hanya dalam bidang filsafatnya melainkan juga dalam bidang disiplin keilmuan lainnya, seperti sejarah dan sastra Arab. Bahkan melalui salah satu master piece-nya yang berjudul Tahżīb al-Akhlāq wa Tatkhīr al-A'rāq namanya menjadi semakin populer di berbagai belahan dunia. Oleh karena itu, dalam kesempatan ini penulis memandang perlu untuk menampilkan sosok Ibnu Miskawaih tersebut dengan stressing kajian pada telaah pemikirannya tentang filsafat al-nafs dan al-akhlak-nya. 


\section{Metodologi Penelitian}

Penelitian ini termasuk penelitian kualitatif, yang jenisnya termasuk kajian pustaka atau library research yakni mengkaji dan meneliti literatur-literatur yang relevan sesuai dengan kajian, seperti buku atau e-book, majalah atau koran, artikel, dan lainnya yang memuat tentang biografi Ibnu Miskawaih. Setiap data yang telah terhimpun dianalisa melalui pendekatan sejarah (historis) yang mempunyai tujuan yaitu untuk mendiskripsikan segala sesuatu yang telah terjadi pada masa lampau. Sehingga dengan metode dan pendekatan yang dilakukan penulis mampu menghasilkan suatu data yang relevan, akurat, tajam dan tepat terhadap perkembangan biografi dan pemikiran Ibnu Miskawaih.

\section{Hasil dan Pembahasan}

\subsection{Biografi Ibnu Miskawaih}

Nama lengkap Ibnu Miskawaih adalah abu Ali Ahmad bin Muhammad bin Ya'qub bin Miskawaih. Ia lahir di Rayy (Teheran, ibu kota Republik Islam Iran sekarang) pada tahun 320 H/ $932 \mathrm{M}$ dan wafat pada usia lanjut di Isfahan pada tanggal 9 Shafar $421 \mathrm{H} / 16$ Februari 1030 M. Ibnu Miskawaih hidup pada masa pemerintahan dinasti Buwaihi di Baghdad (320-450 H/ 932-1062 M) yang sebagian besar permukaannya bermazhab Syi'ah.

Puncak prestasi kekuasaan Bani Buwaih adalah pada mas'Adhud Al-Daulah yang berkuasa tahun 367-372 $\mathrm{H}$, perhatiannya terhadap pengembangan ilmu pengetahuan dan kesusastraan amat besar, sehingga pada masa ini Miskawaih memperoleh kepercayaan untuk menjadi bendaharawan 'Adhud Al-Daulah dan pada masa ini jugalah Miskawaih muncul sebagai seorang filosof, tabib, ilmuan dan pujangga. Tetapi keberhasilan politik dan kemajuan ilmu pengetahuan pada masa itu tidak dibarengi dengan ketinggian akhlak, bahkan dilanda kemerosotan akhlak secara umum, baik dikalangan elite, menengah dan bawah. Tampaknya hal inilah yang memotivasi Miskawaih untuk memusatkan perhatiannya pada etika Islam.

Pada zaman raja 'Adhudiddaulah, Ibu Miskawaih juga mendapat kepercayaan besar dari raja karena diangkat sebagai penjaga (khazin) perpustakaannya yang besar, disamping sebagai penyimpanan rahasianya dan utusannya ke pihak-pihak yang diperlukan. (Ahmad Daudy, 1992)

Sepanjang hidupnya Ibnu Miskawaih dikenal sebagai orang yang sangat commited dengan konsep yang ditulisnya tentang akhlak Artinya antara teori yang dikedepankan dengan tindakan praktisnya slalu sejalan. Bahkan melalui salah satu karyanya yang berjudul Tahzib alakhlak yang kemudian menjadi master piece-nya, dan nama Ibnu Miskawaih menjadi lebih terkenal. (Ahmad Daudy, 1992)

\subsection{Riwayat Pendidikan Miskawaih}

Dari segi latar belakang pendidikannya tidak dijumpai data sejarah yang rinci. Namun dijumpai keterangan bahwa ia mempelajari sejarah dari Abu Bakar Ahmad Ibn Kamil al-Qadhi, mempelajari filsafat dari Ibn al-Akhmar, dan mempelajari kimia dari Abu Tayyib. (Abudin Nata, 2003) Ibnu Miskawaih lebih terkenal dalam bidang filsafat dibandingkan dengan ilmu yang lain, apalagi karya beliau yang sangat terkenal adalah tentang pendidikan dan akhlak. Sehingga beliau lebih banyak menghabiskan waktunya untuk memikir dan belajar secara otodidak tanpa harus berguru kepada yang ahlinya.

Dalam bidang pekerjaan Ibnu Miskawaih adalah bendaharawan, sekertaris, pustakawan, dan pendidik anak para pemuka dinasti Buwahi. Selain akrab dengan penguasa, ia juga banyak 
bergaul dengan ilmuan seperti Abu Hayyan at-Tauhidi, Yahya Ibn 'Adi dan Ibn Sina. Selain itu Ibnu Miskawaih juga dikenal sebagai sejarawan besar yang kemansyhurannya melebihi para pendahulunya, at-Thabari (w. $310 \mathrm{H} / 923 \mathrm{M}$ ) selanjutnya juga ia dikenal sebagai dokter, penyair dan ahli bahasa. Keahlian Ibnu Miskawaih dalam berbagai bidang ilmu tersebut antara lain dibuktikan dengan karya tulisnya berupa buku dan artikel. (Ahmad Daudy, 1992)

Ibnu Miskawaih seorang yang tekun dalam melakukan percobaan-percobaan untuk mendapatkan ilmu-ilmu baru. Selain itu beliau dipercayakan oleh penguasa untuk mengajari dan mendidik anak-anak penjabat pemerintah, hal itu tentu menunjukkan bahwa Ibnu Miskawaih dikenal keilmuannya oleh masyarakat luas ketika itu.

Ibnu Miskawaih juga digelari sebagai Guru ketiga (al-Mualimin al-Tsalits) setelah alFarabi yang digelari guru kedua (al Mualimin al-Tsani) sedangkan yang dianggap guru pertama (al-Mualimin al-Awwal) adalah Aristoteles. Sebagai Bapak Etika Islam beliau telah merumuskan dasar-dasar etika dalam kitabnya Tabdzib al-akhlak wa Tathir alA'raq (pendidikan budi dan pembersihan akhlak). Sementara itu sumber filsafat etika Ibnu Miskawaih berasal dari filsafat Yunani, peradapan Persia, ajaran Syariat Islam, dan pengalaman pribadi. (Muhaimin, 2005) Ibnu Miskawaih adalah seorang teoritis dalam hal-hal akhlak artinya ia telah mengupas filsafat akhlaqiyah secara analisa pengetahuan. Ini tidaklah berarti bahwa Ibnu Miskawaih tidak berakhlak, hanya saja persoalannya ditinjau dari segi pengetahuan semata-mata.

\subsection{Hasil Karya Ibnu Miskawaih}

Ibnu Miskawaih selain dikenal sebagai pemikir (filosuf), ia juga dikenal sebagai penulis produktif. Dalam buku The History of the Muslim Philosophy seperti yang dikutip oleh Sirajuddin Zar disebutkan beberapa tulisannya sebagai berikut:

a. Al Fauz al Akbar (tentang etika)

b. Al Fauz al-Asghar (tentang ketuhanan, jiwa, kenabian, dan metafisika)

c. Tajarib al Umam (sebuah sejarah tentang banjir besar yang ia tulis pada tahun $369 \mathrm{H} /$ $979 \mathrm{M})$

d. Uns al Farid (koleksi anekdot, syair, peribahasa, dan kata-kata hikmah)

e. Tartib al Sa'adat (tentang akhlak dan politik)

f. Al-Mustaufa (tentang syair-syair pilihan)

g. Jawidan Khirad (koleksi ungkapan bijak)

h. Al-Jami' (tentang Ketabiban)

i. Al-Adwiyah (tentang obat-obatan)

j. Kitab al-Ashribah (tentang minuman)

k. Tahzib al-Akhlak

1. Al-Siyar (tentang tingkah laku kehidupan)

Menurut Ahmad Amin sebagaimana dikutip oleh Abuddin Nata, bahwa semua karya Ibnu Miskawaih tidak luput dari kepentingan filsafat dan akhlak. Sehubungan dengan itu Ibnu Miskawaih dikenal sebagai moralis. (Abudin Nata, ) 


\subsection{Pemikiran Ibnu Miskawaih}

Ibnu Miskawaih juga digelari sebagai guru yang ketiga sesudah Aristoteles sebagai guru pertama dan Al-Farabi sebagai guru yang kedua. Ibnu Maskawaih dianggap sebagai guru etika salah satunya adalah karangan beliau yang berjudul Tahzibul Akhlak (Pendidikan Budi) yang sudah dipakai oleh para pakar Pendidikan Agama Islam untuk dijadikan teori terutama tentang adab manusia. Sementara itu sumber filsafat etika Ibnu Miskawaih berasal dari filsafat Yunani, peradaban Persia, ajaran Syariat Islam, dan pengalaman pribadi. Dalam menjelaskan etika islam menurut Ibnu Miskawaih, yaitu:

\subsubsection{Pengertian Akhlak}

Menurut Ibnu Miskawaih, akhlak itu merupakan bentuk jamak dari khuluq, keadaan jiwa yang mengajak atau mendorong seseorang untuk melakukan perbuatan-perbuatan tanpa difikirkan dan diperhitungkan sebelum-nya. (Ibn Miskawaih, 1967)

Dengan kata lain akhlak adalah keadaan jiwa yang mendorong timbulnya perbuatanperbuatan secara spontan. Sikap jiwa atau keadaan jiwa seperti ini terbagi menjadi dua; ada yang berasal dari watak (bawaan) atau fitrah sejak kecil dan ada pula yang berasal dari kebiasaan latihan. (A. Mustofa, 2004) Dengan demikian, manusia dapat berusaha mengubah watak kejiwaan pembawaan fitrahnya yang tidak baik menjadi baik.

Ibnu Miskawaih memandang manusia adalah makhluk yang memiliki keistimewaan karena dalam kenyataannya manusia memiliki daya pikir dan manusia juga sebagai makhluk yang memiliki macam-macam daya. Ibnu Miskawaih menonjolkan kelebihan jiwa manusia atas jiwa binatang dengan adanya kekuatan berpikir yang menjadi sumber tingkah laku, yang selalu mengarah kepada kebaikan.

Mengawali pembahasan tentang akhlak, Ibnu Miskawaih membahas atau memberi beberapa prinsip dasar tentang akhlak, yakni: (Ahmad Daudy, 1986)

1. Tujuan ilmu akhlak adalah membawa manusia kepada kesempurnaan. Kesempurnaan manusia terletak pada pemikiran dan amal perbuatan, yaitu kesempurnaan ilmu dan kesempurnaan amal. Tugas ilmu akhlak terbatas pada sisi amal perbuatan saja.

2. Kelezatan indrawi hanya sesuai dengan hewan tidak dengan manusia. Bagi manusia kelezatan akal adalah yang lebih sesuai dengan martabatnya sebagai manusia. Anak-anak harus di didik sesuai dengan akhlak yang mulia, dimulai dengan jiwa keinginan, lalu jiwa marah, dan akhirnya jiwa berpikir. Rencana pendidikan juga dimulai dengan adab makan, minum, berpakaian (jiwa keinginan), lalu sifat-sifat berani dan daya tahan (jiwa marah), dan akhirnya sifat bernalar, sehingga akal dapat mendominasi segala tingkahlaku (jiwa pikir).

\subsubsection{Keutamaan (Fadhilah)}

Ibnu Miskawaih menyebutkan adanya tiga macam kekuatan jiwa, yaitu bahimiyah dan syahwiyah (kebinatangan atau nafsu syahwat) yang mengejar kelezatankelezatan jasmani, sabu'iyah (binatang buas) yang bertumpu pada lemarahan dan keberanian, dan nathiqah yang selalu berpikir tentang hakikat segala sesuatu. Tiga kekuatan itu saling berdesak dan berebut posisi, jika dapat terjadi keselarasan dalam perimbangan posisi ketiganya, maka tercapailah keutamaan dan kebajikan pada manusia. 
Atas dasar adanya tiga macam kekuatan jiwa manusia itu dapat disebutkan adanya tiga macam keutamaan cabang yang berpokok pada keutamaan-keutamaan dasar itu. Keselarasan antara tiga keutamaan dasar itu menimbulkan keutamaan lain, yang merupakan kesempurnaan ketiga keutamaan dasar tersebut.

Keutamaan jiwa itu ada empat macam, yaitu hikmah (wisdom) adalah keutamaan jiwa cerdas, 'iffah (kesucian) adalah keutamaan nafsu syahwat, syaja'ah (keberanian) adalah keutamaan jiwa ghadhabiyah (sabu'iyah), dan 'adalah (keadilan) adalah keutamaan jiwa yang terjadi dari kumpulan tiga macam keutamaan tersebut di saat terjadi keselaran antara keutamaan-keutamaan itu dan tunduk kepada kekuatan sehat, hingga masing-masing kekuatan itu tidak menuntut kepuasan sejalan dengan wataknya, dan dengan demikian orang akan dapat bersikap adil terhadap dirinya sendiri, juga terhadap orang lain. (A. Mustofa, 1997)

\subsubsection{Kebahagiaan (Sa'adah)}

Ibnu Miskawaih membedakan antara al-khair (kebaikan) dengan al-sa'adah (kebahagiaan). Dimana kebaikan menjadi tujuan semua orang: kebaikan umum bagi seluruh manusia dalam kedudukan sebagai manusia. Sedangkan kebahagiaan adalah kebaikan bagi seseorang, tidak bersifat umum, tetapi relatif tergantung kepada orang per orang. (A. Mustofa, 2004)

Ada dua pandangan pokok tentang kebahagiaan (sa'adah). Yang pertama diwakili oleh Plato yang mengatakan bahwa hanya jiwalah yang mengalami kebahagiaan. Karena itu selama manusia masih berhubungan dengan badan ia tidak akan memperoleh kebahagiaan. Pandangan kedua dipelopori oleh Aristoteles, yang mengatakan bahwa kebahagiaan dapat dinikmati di dunia walaupun jiwanya masih terkait dengan badan. Hanya saja, kebahagiaan berbeda menurut masing-masing orang seperti orang miskin memandang kebahagiaan itu pada kekayaan, dan orang sakit pada kesehatan, dan seterusnya.

Ibnu Miskawaih mencoba mengompromikan kedua pandangan yang berlawanan itu. Menurutnya, karena pada diri manusia ada dua unsur, yaitu jiwa dan badan, maka kebahagiaan meliputi keduanya. Hanya kebahagiaan badan lebih rendah tingkatnya dan tidak abadi sifatnya jika dibandingkan dengan kebahagiaan jiwa. Kebahagiaan yang bersifat benda mengandung kepedihan dan penyesalan, serta menghambat perkembangan jiwanya menuju ke hadirat Allah swt. Kebahagiaan jiwa merupakan kebahagiaan yang sempurna yang mampu mengantar manusia menuju derajat malaikat.

\subsubsection{Cinta (Mahabbah)}

Ibnu Miskawaih memberikan perhatian khusus kepada cinta sebagai salah satu unsur dari etika. Menurutnya cinta ada dua macam; cinta kepada Allah, dan cinta kepada manusia, terutama cinta seorang murid pada gurunya. Cinta yang tinggi nilainya adalah cinta kepada Allah, tetapi cinta tipe ini hanya dapat dicapai oleh sedikit orang. Cinta kepada sesama manusia ada kesamaan antara cinta anak kepada orang tua dan cinta murid kepada guru, tetapi cinta murid kepada guru dipandang lebih mulia dan lebih berperan. Guru adalah bapak rohani bagi murid-muridnya. Gurulah yang mendidik murid-muridnya untuk dapat memiliki keutamaan yang sempurna. Kemuliaan guru terhadap muridnya ibarat kemuliaan rohani terhadap jasmani. (A. Mustofa, 1997) 


\subsubsection{Pendidikan Akhlak}

Dalam karangan-karangan beliau banyak menunjukkan hal-hal yang sifatnya material dalam kontek moral seperti pokok pendidikan akhlaknya ketika mengangkat persoalanpersoalan yang wajib bagi kebutuhan manusia dan jiwa sebagai hal wajib akan menentukan perubahan psikologis ketika terjadi interaksi sesama manusia. (Abuddin Nata, 2003) Dari beberapa uraian diatas memberikan konsekwensi logis, dimana seluruh materi pendidikan pada umumnya merupakan hal yang wajib dipelajari didalam pendidikan moral atau akhlak, seharusnya ilmu-ilmu yang diajarkan dalam proses pendidikan moral tidak hanya diperuntukkan sebagai tujuan akademik semata tetapi akan lebih bermamfaat ketika hal-hal yang bersifat subtansial/esensial dipenerapannya dalam hubungan sosial.

Dapat disimpulkan bahwasanya sifat utama itu antara lain: hikmah, berani, dan murah yang apabila ketiga sifat utama ini selaras, maka sifat keempat akan timbul darinya, yakni keadilan. Sedangkan lawan dari semua sifat itu adalah bodoh, rakus, penakut, dan zalim.

Tujuan pendidikan akhlak yang dirumuskan Ibnu Miskawaih memang terlihat mengarah kepada terciptanya manusia agar sebagai filosuf. Karena itu Ibnu Miskawaih memberikan uraian tentang sejumlah ilmu yang dapat di pelajari agar menjadi seorang filosuf. Ilmu tersebut ialah:

1. Matematika

2. Logika dan

3. Ilmu kealaman

Jadi, jika dianalisa dengan secara seksama, bahwa berbagai ilmu pendidikan yang diajarkan Ibnu Miskawaih dalam kegiatan pendidikan seharusnya tidak diajarkan semata-mata karena ilmu itu sendiri atau tujuan akademik tetapi kepada tujuan yang lebih pokok yaitu akhlak yang mulia. Dengan kata lain setiap ilmu membawa misi akhlak yang mulia dan bukan semata-mata ilmu. Semakin banyak dan tinggi ilmu seseorang maka akan semakin tinggi pula akhlaknya. (Abuddin Nata, 2003)

\section{Kesimpulan}

Ibnu Miskawaih adalah abu Ali Ahmad bin Muhammad bin Ya'qub bin Miskawaih. Lahir di Rayy (Teheran, ibu kota Republik Islam Iran sekarang) pada tahun 320 H/ 932 M dan wafat pada usia lanjut di Isfahan pada tanggal 9 Shafar $421 \mathrm{H} / 16$ Februari $1030 \mathrm{M}$. Ibnu Miskawaih hidup pada masa pemerintahan dinasti Buwaihi di Baghdad (320-450 H/ 932-1062 M) yang sebagian besar permukaannya bermazhab Syi'ah. Ibnu Miskawaih adalah bendaharawan, sekertaris, pustakawan, dan pendidik anak para pemuka dinasti Buwahi. Ibnu Miskawaih juga digelari sebagai guru yang ketiga sesudah Aristoteles sebagai guru pertama dan Al-Farabi sebagai guru yang kedua. Ibnu Maskawaih dianggap sebagai guru etika salah satunya adalah karangan beliau yang berjudul Tahzibul Akhlak (Pendidikan Budi)

Karya karya Ibnu Miskawaih adalah a. Al Fauz al Akbar (tentang etika) b. Al Fauz alAsghar (tentang ketuhanan, jiwa, kenabian, dan metafisika) c. Tajarib al Umam (sebuah sejarah tentang banjir besar yang ia tulis pada tahun 369 H/ 979 M) d. Uns al Farid (koleksi anekdot, syair, peribahasa, dan kata-kata hikmah. Tartib al Sa'adat (tentang akhlak dan politik) f. AlMustaufa (tentang syair-syair pilihan) g. Jawidan Khirad (koleksi ungkapan bijak) h. Al-Jami' (tentang Ketabiban) i. Al-Adwiyah (tentang obat-obatan) j. Kitab al-Ashribah (tentang minuman) k. Tahzib al-Akhlakl. j. Al-Siyar (tentang tingkah laku kehidupan) 
Menurut Ibnu Miskawaih, akhlak itu merupakan bentuk jamak dari khuluq. keadaan jiwa yang mengajak atau mendorong seseorang untuk melakukan perbuatan-perbuatan tanpa difikirkan dan diperhitungkan sebelum-nya. Dengan kata lain akhlak adalah keadaan jiwa yang mendorong timbulnya perbuatan-perbuatan secara spontan. Sikap jiwa atau keadaan jiwa seperti ini terbagi menjadi dua; ada yang berasal dari watak (bawaan) atau fitrah sejak kecil dan ada pula yang berasal dari kebiasaan latihan. Ibnu Miskawaih menyebutkan adanya tiga macam kekuatan jiwa, yaitu bahimiyah dan syahwiyah (kebinatangan atau nafsu syahwat) yang mengejar kelezatan-kelezatan jasmani, sabu'iyah (binatang buas) yang bertumpu pada lemarahan dan keberanian, dan nathiqah yang selalu berpikir tentang hakikat segala sesuatu. Ibnu Miskawaih membedakan antara al-khair (kebaikan) dengan al-sa'adah (kebahagiaan). Dimana kebaikan menjadi tujuan semua orang: kebaikan umum bagi seluruh manusia dalam kedudukan sebagai manusia. Sedangkan kebahagiaan adalah kebaikan bagi seseorang, tidak bersifat umum, tetapi relatif tergantung kepada orang per orang. Ibnu Miskawaih memberikan perhatian khusus kepada cinta sebagai salah satu unsur dari etika. Menurutnya cinta ada dua macam; cinta kepada Allah, dan cinta kepada manusia, terutama cinta seorang murid pada gurunya. Cinta yang tinggi nilainya adalah cinta kepada Allah. Apabila sifat hikmah, berani, dan murah yang apabila ketiga sifat utama ini selaras, maka sifat keempat akan timbul darinya, yakni keadilan. Sedangkan apabila sifat bodoh, rakus, penakut maka akan timbul kedzaliman. Ibnu Miskawaih berpendapat setiap ilmu membawa misi akhlak yang mulia dan bukan semata-mata ilmu. Semakin banyak dan tinggi ilmu seseorang maka akan semakin tinggi pula akhlaknya.

\section{Daftar Pustaka}

Abdurrahman, Muhammad. 2016. Akhlak: Menjadi Seorang Muslim Berakhlak Mulia. Jakarta: Rajawali Pers.

Amin, Ahmad.1993. Al Akhlak, Terj. Farid Ma'ruf. Etika: Ilmu Akhlak . Jakarta: Bulan Bintang.

Ideologi Pendidikan Islam: Paradigma Humanisme Teosentris. Yogyakarta: Pustaka Pelajar.

Ahmadi, Abu. dan Salimi, Noor. 2004. Dasar-dasar Pendidikan Agama Islam. Jakarta: Bumi Aksara.

Asrohah, Hanun. 1999. Sejarah Pendidikan Islam. Jakarta: Logos.

Daulay, Haidar Putra. 2004. Pendidikan Islam dalam Sistem Pendidikan Nasionaldi Indonesia. Jakarta: Kencana Prenamedia Group.

Daudy, Ahmad. 1986. Kuliah Filsafat Isla. Jakarta: Bulan Bintang, 1986

Ilyas, Yunahar. 1999. Kuliah Akhlaq. cetakan I. Yogyakarta: LPPI, HR. Malik no. 1723. Langgulung, Hasan. 1986.

Mahmud, Ali Abdul Halim. 2004. Akhlak Mulia. Jakarta: Gema Insani.

Madkur, Ibrahim. 1991. Filsafat Islam Metode dan Penerapan, terj. Yudian Wahyudi dan Ahmad Hakim al-Mudzakir,Jil. I, Jakarta: Rajawali, 1991

Miskawaih, Ibn. 1967. Tahzib Al Aklaq wa Tathhir A’raq, Kairo: Muassasat AlKhaniji.

Muhaimin, 2005. Kawasan dan Wawasan Studi Islam, Jakarta: Fajar Interpratama Offset. 
Mustofa, A. 1997. Filsafat Islam, Bandung: Pustaka Setia,

Mustofa, A. 2004. Filsafat Islam, Bandung: Pustaka Setia.

Nasution, Harun. 1973. Falsafat dan Mistisis mendalam Islam, Jakarta: Bulan Bintang.

Nata, Abuddin. 2003. Pemikiran Para Tokoh Islam. Jakarta: PT Raja Grafindo Persada.

Masy'ari, Anwar. 2007. Akhlak Al-Qur'an. Surabaya: PT. Bina Ilmu.

Moleong, Lexy J. 2007. Metodologi Penelitian Kualitatif. Bandung: PT Remaja Rosdakarya Offset.

Mulyana, Deddy. 2001. Metodologi Penelitian Kualitatif. Bandung: PT Remaja Rosdakarya.

Munawwir, Ahmad Warson. 1984. Al-Munawwir: Kamus Arab-Indonesia. Surabaya: Pustaka Progressif.

Sugiono. 2009. Metode Penelitian Kuantitatif, Kualitatif dan R\&D. Bandung: Alfabeta. Suharsaputra, Uhar. 2014. Metode Penelitian Kuantitaif, Kualitatif, dan Tindakan. Bandung: PT Refika Aditama.

Suharsimi, Arikunto. 2010. Prosedur Penelitian suatu Pendekatan Praktik. Jakarta: PT Rineka Cipta. 